\title{
Manipulating informational constraints shapes movement reorganization in interceptive actions
}

\author{
Ross A. Pinder • Keith Davids • Ian Renshaw • \\ Duarte Araújo
}

Published online: 15 February 2011

(C) Psychonomic Society, Inc. 2011

\begin{abstract}
Movement organization of cricket batters' actions was analyzed under three distinct experimental task constraints: a representative condition of a practice context in which the batters batted against a "live" bowler, a ball projection machine, and a near life-size video simulation of a bowler. Results showed that each distinct set of task constraints led to significant variations in the patterns of movement control. Removal of advanced information sources from a bowler's actions when the batters faced the ball projection machine caused significant delays in movement initiation, resulting in reduced peak bat swing velocities and a reduction in the quality of bat-ball contact, when compared with batting against a "live" bowler. When responding to a two-dimensional video simulation, batters were able to use information from the bowlers' action, enabling fidelity of initial behavioral responses consistent with the task of batting against a "live" bowler. However, without interceptive task requirements or actual ball flight information, significant variations in downswing initiation timing and peak bat velocities were demonstrated. Findings stress the need for representative experimental and learning designs in fast ball sports for developing performers.
\end{abstract}

Keywords Movement organization - Interceptive actions . Representative design · Task constraints · Fast ball sports

R. A. Pinder $(\triangle) \cdot$ K. Davids $\cdot$ I. Renshaw

School of Human Movement Studies,

Queensland University of Technology,

Victoria Park Road, Kelvin Grove,

QLD 4059, Brisbane, Australia

e-mail: ross.pinder@qut.edu.au

D. Araújo

Faculty of Human Kinetics, Technical University of Lisbon,

Lisbon, Portugal
Interceptive actions have been used as highly effective task vehicles for developing theoretical understanding of the synergetic relationship of information and movement under severe time constraints (e.g., Caljouw, van der Kamp, \& Savelsbergh, 2004; Le Runigo, Benguigui, \& Bardy, 2005; Montagne, Laurent, Durey, \& Bootsma, 1999). Temporal demands in fast ball sports often exceed the intrinsic limitations in visuomotor delays and movement times (van der Kamp, Rivas, van Doorn, \& Savelsbergh, 2008), as exemplified by the margin for error in the interceptive timing of a cricket batting stroke, reported to be in the region of $2.5 \mathrm{~ms}$ (Regan, 1997). To cope with such task constraints, skilled performers are able to use perceptual information to produce extremely high levels of precision. Consequently, there has been a significant increase in research examining perceptual-motor skill in fast ball sports - particularly, in assessing visual anticipation. In this respect, performers consistently show an ability to use advanced kinematic information from the actions of opponents (e.g., Abernethy \& Zawi, 2007; Jackson \& Morgan, 2007; Müller \& Abernethy, 2006; Renshaw \& Fairweather, 2000) and early ball flight information (e.g., Land \& McLeod, 2000; Müller et al., 2009) to guide their actions.

However, a major concern of typical studies of perceptual-motor expertise has been the neglect of the role of the environment, which is in alignment with similar limitations in psychological science (see Brunswik, 1956; Davids, 2008; Davids, Button, Araújo, Renshaw, \& Hristovski, 2006; Dhami, Hertwig, \& Hoffrage, 2004; Dunwoody, 2006; Hammond \& Stewart, 2001). This concern was epitomized by Egon Brunswik over half a century ago when outlining the concept of representative design and emphasizing the importance of organism-environment relations in the study of human behavior. On the whole, 
Brunswikian concepts still have not been integrated into psychological research (Rogers, 2008), with researchers traditionally opting for systematic designs for experimental control, jeopardizing the generalizability of research findings (Araújo, Davids, \& Passos, 2007). Generalizability is central to the ideals of Brunswik's notion of representative experimental design, which proposes that experimental stimuli must be sampled from an organism's natural environment so as to be representative of the stimuli to which it is adapted and to which experimental data are intended to be generalized (Brunswik, 1956). Brunswikian concepts are harmonious with the tenets of Gibson's (1979) theory of direct perception, which emphasized the reciprocal relations between processes of perception and action in organism-environment interactions. In studies of sport, representative design supports the need for the generalization of task constraints in experiments to the task constraints encountered during different performance contexts-for example, perceiving the actions of a "live" opponent in a study of anticipation (Araújo, Davids, \& Hristovski, 2006; Davids, 2008).

Previous research on perceptual-motor skill in sport has been criticized for failing to maintain the functional coupling of perception and action processes in experimental designs (e.g., Dicks, Davids, \& Araújo, 2008; van der Kamp et al., 2008). Some studies of perception and action have demonstrated significant differences in visuomotor behaviors observed between laboratory conditions and task conditions representative of performance contexts (e.g., video simulation vs. in situ tasks; see Dicks, Button, \& Davids, 2010; Mann, Williams, Ward, \& Janelle, 2007). Specifically, the limitations of the ubiquitous occlusion and video simulation methodologies have been attributed to the removal of key sources of information in experimental design and a failure to ensure that neuroscientific knowledge of visual system functioning underpins research designs (e.g., Davids, 2008; van der Kamp et al., 2008). Traditionally,experimental designs have not ensured that selected task constraints support the use of functional information-movement couplings. That is, environmental information presented in experimental tasks and the action responses required (e.g., verbal, written, or simplified movements) do not allow performers to replicate the same perception and action processes as those displayed in representative performance environments. Research has typically been focused on substantiating expertise effects, rather than on comparing participant movement behaviors across varying task constraints. As a result, research needs to develop a principled theoretical rationale for this line of work to provide a comprehensive framework to guide future experimentation on perceptual-motor performance in sport (Pinder, Davids, Renshaw, \& Araújo, in press). The integration of Brunswikian and Gibsonian ideas proposes that in order to attain representative experimental design, experimental tasks need to allow participants opportunities to pickup and use specifying information from the environment to support functional movement responses (i.e., perception-action coupling; for an overview, see Warren, 2006).

In spite of the widely stressed importance of perceptual skills in fast ball sports (Abernethy, Zawi, \& Jackson, 2008; Shim, Carlton, \& Kwon, 2006; Weissensteiner, Abernethy, Farrow, \& Müller, 2008; Williams \& McRobert, 2008), much research has analyzed performers' responses in typical performance environments, using ball projection machines to enhance experimental control of projectile trajectories. For example, in studies of cricket batting, ball projection machines have been used in experiments to assess gaze behaviors (Croft, Button, \& Dicks, 2010; Land \& McLeod, 2000), visual function (Mann, Ho, De Souza, Watson, \& Taylor, 2007), and movement organization (primarily temporal responses between skill levels; Weissensteiner, Abernethy, \& Farrow, 2009). However, the use of ball projection machines (with velocities ranging from 26 to $30 \mathrm{~m} \cdot \mathrm{s}^{-1}$ ) has revealed significant differences in the spatiotemporal responses of performers (skilled and experienced to lessskilled and developmental juniors), when compared with facing a "live" bowler projecting a ball at the same speed (Gibson \& Adams, 1989; Pinder, Renshaw, \& Davids, 2009; Renshaw, Oldham, Davids, \& Golds, 2007). These findings are consistent with the data observed in the use of such machines in other sports (e.g., tennis; Shim, Carlton, Chow, \& Chae, 2005).

Therefore, the current understanding of perceptualmotor expertise in sport (in both visual perception and technique analysis) may have been compromised through use of experimental designs that are not representative of performance contexts (i.e., facing a "live" bowler). Not only is this a critical concern for perceptual-motor research, but it also has major consequences for learning and practice design in fast ball sports, where the use of ball machines is ubiquitous, particularly in skill development programs for junior performers. During learning, performers attempt to converge on useful perceptual variables to support action in specific performance environments (e.g., perceptual attunement; Fajen, Riley, \& Turvey, 2009; Gibson, 1966; Jacobs \& Michaels, 2002). Intuitively, the removal of critical perceptual information sources (particularly during early learning or important developmental stages) may limit the development of performers' ability to detect reliable information to support action (e.g., the creation of information-movement couplings and their refinement over time; Araújo, 2007; Davids, Renshaw, \& Glazier, 2005; Jacobs \& Michaels, 2002). Changing the informational constraints on action might result in less representative practice designs and changes to a performer's acquisition of 
functional movement control. This idea has been exemplified in cricket batting research, where Stretch, Buys, Du, Toit, and Viljoen (1998) demonstrated that batters adapted spatiotemporal characteristics of emergent action when facing a "live" opponent, depending on the required shot response to different bowling trajectories, through the pickup of advanced kinematic information and early ball flight. These adaptations to action ensured that batters contacted the ball at the right time with the correct spatial orientation (Savelsbergh \& Bootsma, 1994). As a result, when facing a "live" bowler, experienced batters executed attacking drives that reached peak horizontal velocity $0.02 \mathrm{~s}$ before bat-ball contact (Stretch et al., 1998), consistent with findings in other fast ball sports (e.g., baseball, McIntyre \& Pfautsch, 1982; softball, Messier \& Owen, 1984; golf, Shibayama \& Ebashi, 1983). Despite these findings, very little work has focused on how differing spatiotemporal responses under varying task constraints affect batting performance outcomes or bat velocity (force control), beyond simple performance measures (see, e.g., Mann, Abernethy, \& Farrow, 2010). Clearly, further work is needed to compare perceptual-motor organization when batters bat against a "live" performer and against ball projection machines, to observe how advance kinematic information from a bowler's actions shapes behavior.

In one exception, Taliep, Galal, and Vaughan (2007) compared the kinematic variables of performance by skilled and less-skilled cricket batters when completing "shadow" front foot drives (an attacking shot) against "realistic projected video footage" in a screened simulation of the performance environment. However, since no comparative studies of movement behavior under video simulation conditions and a representative task of batting against a "live" opponent currently exist, it is not understood whether life-size video simulations provide a representative task for batters. This lack of clarity is due mainly to the removal of the interceptive action in many simulation designs (e.g., decoupling of perception and action) and to previous research showing differences in information pickup from 2-D video displays, as compared with natural performance environments (see Dicks et al., 2010). Furthermore, without knowledge of the manipulation of ball length in previous studies (varying perceptual information and ball trajectories), it is unknown whether batters can attune to small but critical changes in delivery characteristics (e.g., between two different ball landing positions) when that information is presented in video simulations. Critical information may be removed completely (e.g., removal of a bowler's movements when ball projection machines are used), but it may also be present but much harder to detect in a 2-D display than in the natural performance environment.

To assess the degree of association between behavior under different task constraints, the fidelity of the action response can be assessed by measuring task performance in detail (Araújo et al., 2007; Stoffregen, Bardy, Smart, \& Pagulayan, 2003; see also van der Kamp et al., 2008). Therefore, the aims of the present study were to compare spatiotemporal movement organization, bat velocity, and interceptive ability (quality of bat-ball contact between interceptive conditions; see Müller \& Abernethy, 2008) of cricket batters across three distinct tasks typically used in experimental and learning design. For this purpose, the movement organization of cricket batters' actions when performing an attacking and a defensive shot was compared under three distinct experimental task constraints against (1) a "live" bowler, (2) a ball projection machine, and (3) a near life-size, 2-D video simulation of the same bowler delivering a ball. It was predicted that spatiotemporal responses when batting against a "live" bowler would differ markedly with performance in both the ball projection machine and video simulation constraints, with these conditions varying the degree to which the movement responses and available information are representative of the performance environment. It was also predicted that bat velocity would differ significantly under video simulation conditions, with lower peak velocities observed with the removal of the interceptive task requirement and ball flight information, which has been shown to change prospective movement control (Montagne, 2005; Müller et al., 2009). Furthermore, analyses of attacking and defensive shots were expected to reveal further insights into the process of coupling of movement to information in a dynamic interceptive action. These analyses were expected to demonstrate possible consequences for movement organization of employing ball projection machines in research and learning designs, which remove advance kinematic (i.e., preball release) information from the bowler's actions (see, e.g., Weissensteiner et al., 2009).

\section{Method}

\section{Participants}

Twelve cricket batters (age: $15.6 \pm 0.7$ years) with $6.6 \pm$ 0.6 years of competitive junior cricket experience were recruited for the study. All the participants provided informed consent, and ethical clearance was completed through a university ethics committee. Four left-arm bowlers (age = $15.0 \pm 0.8$ years) with similar conventional bowling actions (ACB, 1998) and physical attributes (average height of release $=2.06 \pm 0.07 \mathrm{~m}$; average bowling speed $=28.14 \pm$ $0.56 \mathrm{~m} \cdot \mathrm{s}^{-1}$ ) were also recruited for the study. All the bowlers were appropriately matched to the batters' performance level and experience. Bowling speed was assessed for the four bowlers using a sports radar gun (Stalker Radar, Texas). 


\section{Procedure}

Performance observations occurred in the participants' regular indoor practice facility. Participants undertook three distinct experimental tasks: batting against (1) a "live" bowler, (2) a ball machine, and (3) a video simulation, in a fully counterbalanced design to control for order and learning effects. None of the 12 participants had previously faced any of the four bowlers but had faced bowlers of similar speed and ability in training. All the participants had some limited experience of batting against a ball machine ( $<30$ trials per week during years of competitive experience); however, none had any experience of video-based simulation training. Two weeks prior to data collection, all the participants completed six blocks of 6 trials $(6$ cricket "overs," resulting in 36 trials) of "simulated batting" against the video-based simulation, which allowed participants to become familiarized with the equipment and trial procedures. These trials were completed against footage of different bowlers with abilities similar to those used in the data collection phase of the study, to ensure that findings were not influenced by any possible learning effects caused by exposure to the specific bowlers' movements.

The same balls ("Oz" bowling machine ball) were used across all conditions (including filming of the video simulation video trials) to provide consistency of bounce to participants. The ball machine (Jugs Inc., Tualatin, Oregon) was set to the mean height of release and bowling speed recorded from the four bowlers in order to replicate their typical delivery characteristics (e.g., bowling trajectory). The same highly experienced Australian level 3 coach operated the ball machine for all the participants, using a typical standardized predelivery routine, in which the operator held the ball up for the batter to see before lowering it directly into the ball machine (see Renshaw et al., 2007; Shim et al., 2005). The time between release from the operator's hand and the ball's emerging from the machine head (approximately $1 \mathrm{~s}$ ) was consistent for all release trajectories. The sound produced by the ball machine also provided information that the batters could use to predict when the ball would be released (Shim et al., 2005).

Deliveries were randomized across all conditions. Both front and back foot shots were included to alleviate any bias in batters' responses and to ensure that the experimental setup did not direct perceptual choices (i.e., limit batters' choices to just the two shots of interest). Bowlers followed a randomized script for ball target locations, which was replicated in the ball machine condition. Importantly, the ball machine allowed for subtle but critical changes in delivery trajectory, prior to the appearance of the ball, that were undetectable by these participants, alleviating the concern that a ball machine provides too much predictability of ball trajectory characteristics (Gibson \& Adams, 1989; Renshaw et al., 2007).

Participants were instructed under all conditions to perform as they would in a match situation, by attempting to score as many runs as they could while avoiding being bowled. No further instruction or knowledge of the experimental aims was provided. In the video simulation conditions, participants were asked to replicate the shot they would play against a "real ball" in each situation, producing coupled responses to the video footage.

Participants generally faced 36-40 deliveries in each of the interceptive conditions (ball machine and bowler) to generate the required number of shots for data analysis, in line with previous empirical research (Stretch et al., 1998). Participants faced 36 randomized trials under video screen conditions. Two common strokes in cricket (the forward defensive stroke and the front foot straight drive) that have been the focus of previous research (Stretch et al., 1998) were used to assess movement timing and control of action across the distinct experimental tasks. These strokes are widely considered as basic performance foundations, with experiential knowledge and empirical research suggesting that with modifications, the forward defensive shot provides the basis for the attacking straight drive (Stretch et al., 1998; Woolmer, Noakes, \& Moffett, 2008). Importantly, the two shots require the batter to discriminate ball delivery characteristics (i.e., pickup of trajectory information to determine the pitching location) between a ball that bounces closer to the batter (2-3 $\mathrm{m}$ from the batter's preparatory position; see Fig. 1) and affords an attacking drive and a ball that pitches farther from the batter (4-5 m), requiring a defensive response.

Video preparation and screen setup

Required video simulation footage of the four bowlers was filmed (Sony HVR-V1P) from the batters' preparatory position at the batting crease in the same indoor facility as that in the "live" bowler and ball machine conditions. A marking grid on the floor $(0.4 \times 1 \mathrm{~m}$ areas; see Fig. 1$)$, in line with the batting stumps, enabled the ball-pitching location (direction and distance from the batting stumps) to be recorded for each video trial. Trials were randomized in a test package (with an equal number of deliveries from each bowler), requiring the participant to respond with a range of both front and back foot movements, with no prior knowledge of upcoming deliveries. Knowledge of the bounce point for each trial allowed for consistency across all three conditions. Video simulation footage was projected onto a large screen $(2.6 \times 3.5 \mathrm{~m})$ situated $3 \mathrm{~m}$ from the popping crease (position of participants' preparatory stance), allowing an approximate subtended visual angle of $7^{\circ}$ and a virtual distance of $17.7 \mathrm{~m}$. This setup provided a 
Fig. 1 Experimental setup for "live" bowler, ball machine, and video simulation conditions, respectively
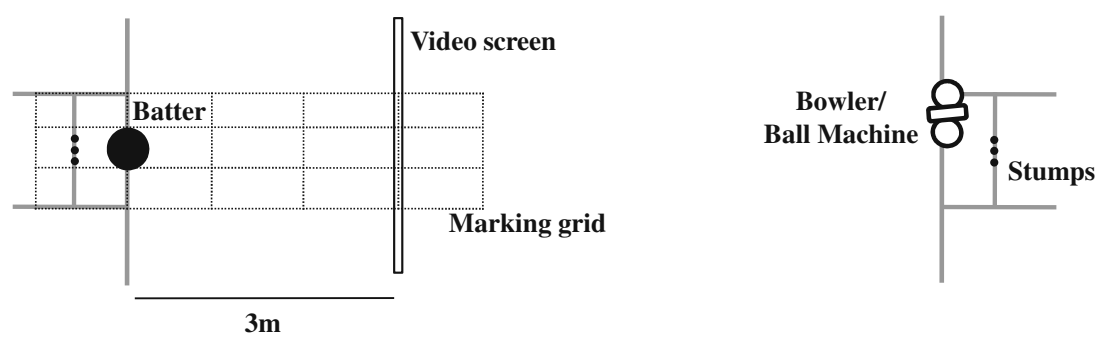

$17.7 \mathrm{~m}$ (distance between creases)

20.12m (pitch length)

near life-size image of the bowler at the moment of ball release, in accordance with methods in both cricket (Taliep et al., 2007) and soccer (Dicks et al., 2010) goalkeeping research.

Data collection

Two synchronized cameras (Sony HVR-V1P) were used to simultaneously capture participant movements (located $10 \mathrm{~m}$ from the sagittal plane of action perpendicular to the batting crease) and the point of ball release, following established setup procedures (Bartlett, 2007). Cameras were set at a frame rate of $100 \mathrm{~Hz}$ and a shutter speed of 1/300 s. Calibration was attained using horizontal and vertical references of known distance. Participants wore full protective equipment (including batting helmets) in all conditions, and contrasting markers were placed on the top and bottom edges of the bat and the proximal phalanx of the first and fifth toes (for front and back feet, respectively). These markers allowed analysis of step lengths and bat swing characteristics, including peak bat swing height and linear horizontal bat velocity. Pilot work and previous empirical research (Renshaw et al., 2007; Stretch et al., 1998) have demonstrated that the measured aspects are suitably planar to allow for this type of analysis. Key phases (dependent variables) of the batting action were identified as (1) point of ball release, (2) initiation of backswing of the bat, (3) initiation of the front foot movement, (4) initiation of the downswing of the bat, (5) placement (planting) of the front foot, and (6) point of batball contact (see Renshaw et al., 2007; Stretch et al., 1998). Moment of ball release was recorded as the first frame after the ball had left either the bowler's hand (in "live" and video conditions) or the mouth of the ball projection machine. Front foot movement initiations and placements were defined as the first frame after the foot had lifted off and been placed on the ground, respectively. Initiations of backswing and downswing were identified within the data on the basis of acceleration patterns of the bat endpoint and were confirmed using frame-by-frame analysis (due to preparatory movements). Timing of the predicted point of bat-ball contact when the batter faced the video screen was determined by three high-level cricket coaches (English Cricket Board levels 2 and 3), in accordance with previous work (Taliep et al., 2007). Coaches viewed synchronized video of the presented video trial and the batter's responses and predicted the point at which bat-ball contact would have occurred. Coaches' predictions were highly consistent with each other (within $0.03 \mathrm{~s}$ ) and in line with previous findings (Taliep et al., 2007). The average frame number provided by the three coaches' assessments was taken as the point of predicted bat-ball contact. Two-way (experimental task $\times$ shot) repeatedmeasures analyses of variance (ANOVAs) confirmed that there were no significant differences across conditions, $F(2,142)=0.09, p>.05$, or shot type, $F(1,71)=0.02, p>.05$, in the timing between release and bat-ball contact ("live" bowler or ball machine) or predicted contact (video simulation).

\section{Dependent measures}

\section{Quality of bat-ball contact}

A measure of quality of bat-ball contact (QOC), validated by Müller and Abernethy (2008), was used as a simple but reliable tool for assessing interceptive success under both "live" bowler and ball machine task constraints. A trained observer provided a QOC score for each trial in line with the validated measure. The scores where defined as (1) the ball contacting the bat and traveling in a direction consistent with the precontact plane of bat motion/ swing (2 points), (2) the ball contacting the bat but deflecting in a direction inconsistent with the precontact plane of bat motion/swing (1 point), and (3) the ball not making contact with the bat ( 0 points). Reliability was assessed on a selection of 42 trials $(10 \%)$. Intrarater reliability was assessed by comparing two video reviews (with a 4-week break) of the first observer, while inter-rater reliability was assessed by comparing the scores of the first observer with those of a second observer. Strong correlations were found for both intra- $\left(r_{\mathrm{s}}=.87\right)$ and inter-rater $\left(r_{\mathrm{s}}=.86\right)$ reliability, consistent with previous work (Mann et al., 2010). 


\section{Temporal phasing}

For each condition, means and standard deviations of movement timing data (in seconds) were recorded for each of the key initiation points, relative to ball release. Unless stated, data were calculated in seconds (mean \pm standard deviation) before bat-ball contact (or predicted contact), with point of ball release occurring $0.64 \mathrm{~s}$ before bat-ball contact.

\section{Bat velocity, peak bat swing height, and step length}

Trials were analyzed using SIMI motion software (SIMI Reality Motion Systems GmbH). Data were smoothed using a 4th-order Butterworth recursive filter with a cutoff frequency of $4.5 \mathrm{~Hz}$. Coordinates of the digitizing process were used to calculate linear horizontal velocity of the bat throughout the action, peak height of the bat swing, and step length at bat-ball (or predicted) contact. Bat swing height was recorded as the peak height attained throughout the batter's action, and step length was measured between foot markers at the moment of bat-ball (or predicted) contact. Digitizer accuracy was assessed using the intraclass correlation coefficient for both intra- (ICC $=.96)$ and interrater (ICC $=.94)$ reliability measures, considered to demonstrate high-to-excellent reliability within the relevant literature (Atkinson \& Nevill, 1998; see also Vincent, 1994).

\section{Data analysis}

Video trials used for analysis were initially evaluated to ensure consistency of responses and delivery characteristics (ball bounce location) across all three conditions. In line with similar work (Shim et al., 2005), trials demonstrated that participants did not preempt the ball machine delivery, nor did they make early movements forward or backward and have to correct their original decision. Six forward defensive and six forward drive shots were analyzed for each participant in each condition, resulting in a total of 422 trials (12 participants $\times 3$ experimental tasks $\times 2$ shot responses $\times 6$ trials). Separate two-way (experimental task $\times$ shot) within-subjects ANOVAs with repeatedmeasures on both factors were used to analyze the data on all dependent measures. In cases of violation of the sphericity assumption, a Greenhouse-Geisser correction was used to adjust the degrees of freedom for treatment and error terms of the repeated measures variables in the ANOVAs. Following these analyses, post-hoc pairwise comparisons were undertaken to assess which comparisons were statistically significant in each instance. Paired ttests were used to assess differences across experimental task for both shot types. Bonferroni adjustments were used in all cases to control for type I error (Field, 2009) resulting from any interdependence within dependent measures. Finally, partial eta-squared $\left(\eta_{\mathrm{p}}{ }^{2}\right)$ values were provided for each ANOVA to provide an indication of the effect size for each factor or interaction of factors.

\section{Results}

Quality of bat-ball contact

The ANOVA for QOC scores ("live" bowler vs. ball machine; see Fig. 2) revealed main effects for both experimental task, $F(1,71)=31.76 . p<.01, \eta_{\mathrm{p}}{ }^{2}=.31$, and shot type $F(1,71)=$ 14.99, $p<.01, \eta_{\mathrm{p}}^{2}=.17$, with significantly higher scores under "live" bowler task constraints $(p<.01)$ and when the batter responded with a forward drive $(p<.05)$.

\section{Front foot movement}

Front foot movement characteristics were significantly shaped by experimental task constraints (comparison of all three conditions; see Figs. 3 and 4). There was a main effect for experimental task on the timing of front foot initiation, $F(2,142)=67.92, p<.01, \eta_{\mathrm{p}}^{2}=.49$, primarily due to a significant delay when under ball machine constraints, for both drive $(p<.01)$ and defense $(p<.01)$ shots. Similarly, main effects for both experimental task constraints, $F(2,142)=26.13, p<.01, \eta_{\mathrm{p}}^{2}=.27$, and shot type, $F(1,71)=7.75, p<.01, \eta_{\mathrm{p}}{ }^{2}=.10$, were found for the timing of front foot placement, with later (i.e., closer to bat-ball contact) placements occurring under ball machine task

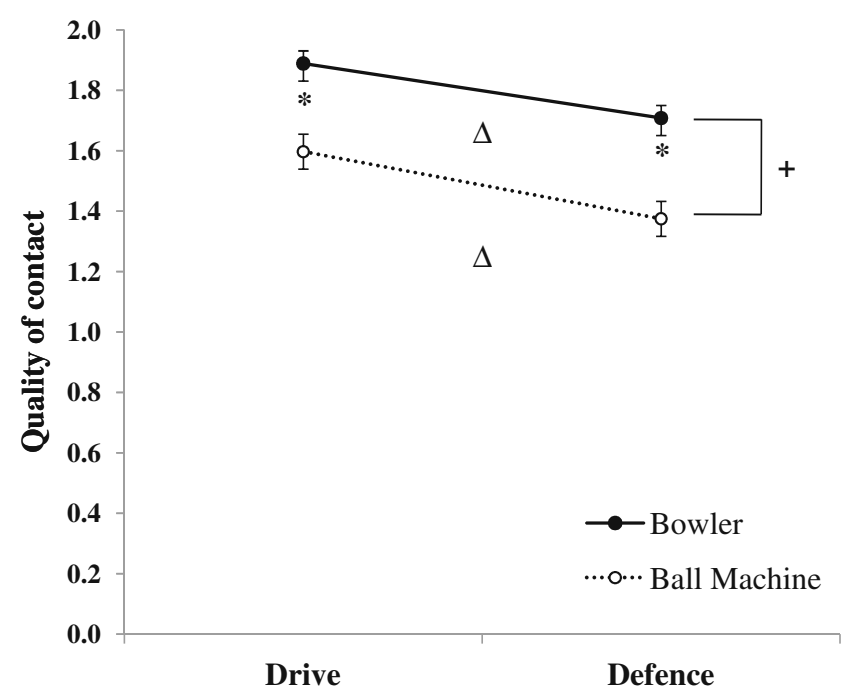

Fig. 2 Mean group batting quality of contact scores across interceptive experimental task constraints (bowler and ball machine) and shot type. Data are represented with standard errors. ${ }^{\text {*Significant }}$ differences between experimental task constraints $(p<.01)$. ${ }^{+}$Significant differences in scores collapsed across experimental condition for shot type $(p<.05) .{ }^{\Delta}$ Experimental task-specific differences for drive and defensive shots $(p<.05)$ 
Fig. 3 Differences in the timing and initiation of front foot movement (FFM) and front foot placement (FFP) relative to bat-ball contact, when three distinct experimental tasks were faced. *Significant differences between experimental task constraints $(p<.05) .{ }^{* *}$ Significant differences between experimental task constraints $(p<.01) .{ }^{+}$Significant differences in scores collapsed across experimental condition for shot type $(p<.01)$

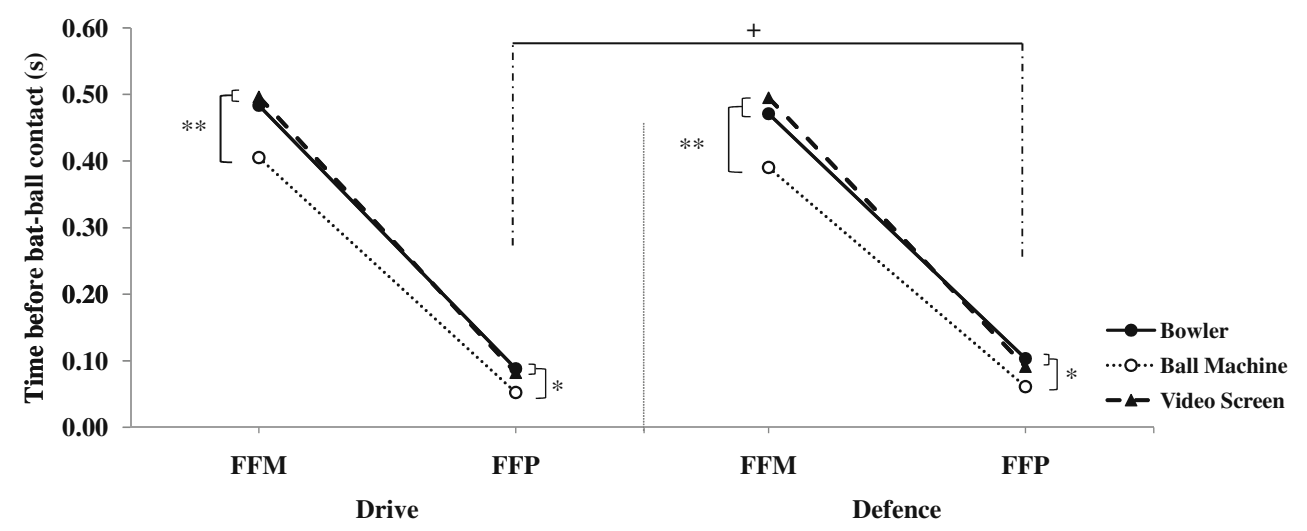

constraints $(p<.05)$ and when a forward drive was performed $(p<.01)$.

There were significant main effects for both experimental task constraints, $F(2,142)=7.35, p<.01, \eta_{\mathrm{p}}{ }^{2}=.09$, and shot type, $F(1,71)=182.69, p<.01, \eta_{\mathrm{p}}{ }^{2}=.72$, for batters' front foot step lengths (see Fig. 5), which were shorter under ball machine task constraints $(p<.01)$ and when forward defensive shots were performed $(p<.01)$.

\section{Bat swing}

A significant main effect revealed that backswing initiation time was affected by experimental task constraints, $F(2,130)=67.33, p<.01, \eta_{\mathrm{p}}{ }^{2}=.51$, primarily due to backswing initiation's occurring significantly later against the ball projection machine, as compared with both the "live" bowler and the video simulation conditions (see Fig. $4 ; p<.01$ ). Similarly, main effects for both experimental task, $F(2,142)=26.26, p<.01, \eta_{\mathrm{p}}{ }^{2}=.27$, and shot type, $F(1,71)=80.54, p<.01, \eta_{\mathrm{p}}{ }^{2}=.53$, demonstrated that experimental task design influenced the timing of the downswing initiation. There were significant differences in timing of downswing initiation when the batters faced the ball machine, as compared with both the live bowler $(p<.01)$, and video simulation $(p<.05)$ task constraints. In contrast with observations on backswing initiation, there

were also differences in the timing of downswing initiation between the "live" bowler and video simulation constraints, with initiation occurring significantly earlier when a video screen was faced $(p<.01)$. Additionally, the downswing was initiated significantly later (see Fig. 3) under all three experimental task constraints when an attacking shot was used $(0.18 \pm 0.05 \mathrm{~s})$ as compared with a defensive shot $(0.22 \pm 0.06 \mathrm{~s})$.

There were significant main effects for both experimental task constraints, $F(2,130)=14.78, p<.01, \eta_{\mathrm{p}}{ }^{2}=.19$, and shot type, $F(1,65)=138.95, p<.01, \eta_{\mathrm{p}}{ }^{2}=.68$, on peak backswing height attained by participants (see Fig. 5). Post hoc analysis revealed that significantly shorter backswing heights were attained when a ball machine was faced than in the "live" bowler $(p<.01)$ or video simulation $(p<.01)$ tasks. Analysis also revealed a significant difference between shot type and peak backswing height, with batters demonstrating higher peak backswings when using an attacking shot $(p<.01)$.

\section{Bat speed}

Table 1 summarizes the mean group data for the peak horizontal velocity attained during the batter's action and the time during the downswing at which the peak velocity occurred, relative to bat-ball (or predicted) contact. There
Fig. 4 Differences in the timing and initiation of backswing (BS) and downswing (DS) relative to bat-ball contact, when three distinct experimental tasks were faced. "Significant differences between experimental task constraints $(p<.05) .{ }^{* *}$ Significant differences between experimental task constraints $(p<.01)$.

${ }^{+}$Significant differences in scores collapsed across experimental condition for shot type $(p<.01)$

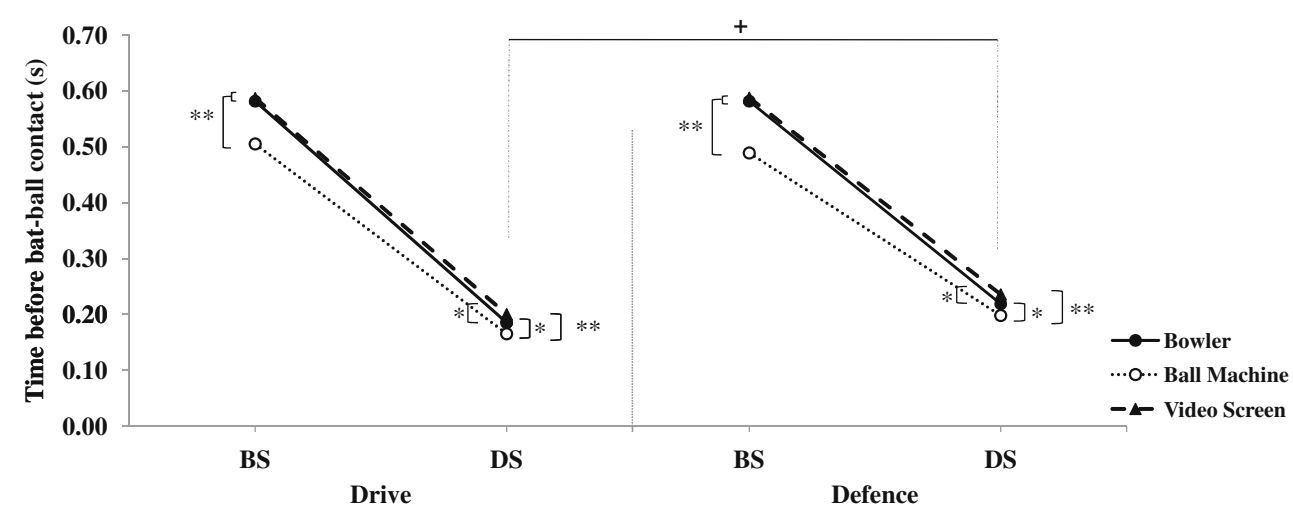


Fig. 5 Mean group differences in peak backswing heights (above left) and step lengths (above right) during an attacking and a defensive shot under three distinct experimental task constraints (error bars represent standard deviations). " Significant differences between experimental task constraints $(p<.01) .{ }^{+}$Significant differences in scores collapsed across experimental condition for shot type $(p<.01)$
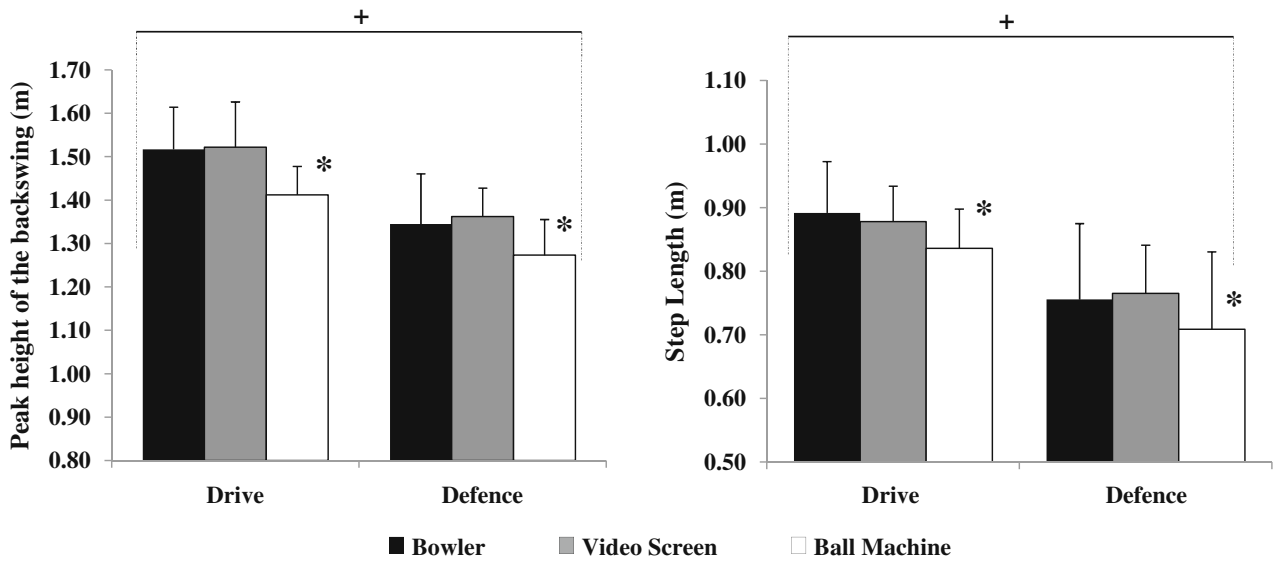

were significant main effects for peak horizontal velocity of the bat endpoint for experimental task constraints, $F(2,142)=$ $37.18, p<.01, \eta_{\mathrm{p}}{ }^{2}=.34$, and shot type, $F(1,71)=870.46$, $p<.01, \eta_{\mathrm{p}}{ }^{2}=.93$. Batters achieved higher peak bat velocities when batting against a "live" bowler than in both ball machine and video screen conditions $(p<.01)$. There was also a significant interaction between experimental task constraints and shot type, $F(2,142)=13.39, p<.01, \eta_{\mathrm{p}}{ }^{2}=$ .16 , predominantly due to the significant decrease in mean peak horizontal velocity for the forward defensive shot under video simulation conditions $(p<.01)$. Furthermore, significant main effects were found for the timing of peak velocity across both experimental task constraints, $F(2,142)=33.41, p<.01$, $\eta_{\mathrm{p}}{ }^{2}=.66$, and shot type, $F(1,71)=136.09, p<.01, \eta_{\mathrm{p}}{ }^{2}=.32$. Significant differences in timing of peak bat swing were found between batting under video simulation conditions for both the drive and defense, when compared with both "live" bowler $(p<.01)$ and ball machine $(p<.01)$ tasks. Results displayed a significant interaction between experimental task constraints and shot type, $F(2,142)=7.91, p<.05, \eta_{\mathrm{p}}{ }^{2}=.10$. Fig. 6 displays the grouped mean horizontal bat velocity for the forward drive. Note that the time at which peak velocity occurred relative to bat-ball (or predicted) contact indicates not only the different peaks across the experimental tasks, but also a dissimilar curve shape for the bat endpoint velocity in the video simulation task due to the removal of the bat-ball contact.

\section{Discussion}

The design of experimental task constraints that effectively capture organism-environment relationships remains a prominent concern in experimental psychology (Brunswik, 1956; Dhami et al., 2004; Dunwoody, 2006; Rogers, 2008). This study provided evidence to support current concerns expressed by perceptual-motor behavior researchers over the generality of performance data from experimental and learning tasks to performance contexts, such as sport (cf. Dicks et al., 2010; van der Kamp et al., 2008). Data revealed significant changes in timing and organization of junior cricket batters' movements under different task constraints. These findings have major implications for learning design at these important developmental stages of learning in ball sports such as cricket, particularly due to the heavy use of ball projection machines in many training programs.

\section{"Live" bowler-ball projection machine comparisons}

The most pronounced differences observed in the data demonstrated that even simple performance measures, such as QOC and bat swing velocities, are significantly affected by the removal of key sources of perceptual information. Batters demonstrated definitive movement initiation effects (backswing and front foot) shortly after ball release when
Table 1 Peak horizontal bat endpoint velocity $\left(\mathrm{m} \cdot \mathrm{s}^{-1}\right)$, and time (in seconds) at which peak velocity occurred relative to bat-ball or predicted bat-ball point of contact, for forward drive and forward defensive shots

\begin{tabular}{|c|c|c|c|c|c|c|c|c|}
\hline & \multicolumn{4}{|c|}{ Peak Bat Velocity } & \multicolumn{4}{|c|}{ Timing of Peak Velocity } \\
\hline & \multicolumn{2}{|l|}{ Drive } & \multicolumn{2}{|c|}{ Defense } & \multicolumn{2}{|l|}{ Drive } & \multicolumn{2}{|c|}{ Defense } \\
\hline & $M$ & $S D$ & $M$ & $S D$ & $M$ & $S D$ & $M$ & $S D$ \\
\hline Bowler & 11.38 & 1.75 & 7.37 & 1.45 & -0.01 & 0.02 & -0.03 & 0.02 \\
\hline Ball projection machine & 10.62 & 1.89 & 7.32 & 1.37 & -0.02 & 0.02 & -0.03 & 0.01 \\
\hline Video screen & 10.31 & 1.82 & 5.25 & 1.71 & 0.01 & 0.02 & -0.02 & 0.03 \\
\hline
\end{tabular}


Fig. 6 Mean group horizontal bat endpoint velocities for the forward drive shot across three distinct experimental tasks. (N. B. Data peaks do not align with analyzed data in Table 1 , due to peak horizontal velocities' occurring at differing times across all trials)

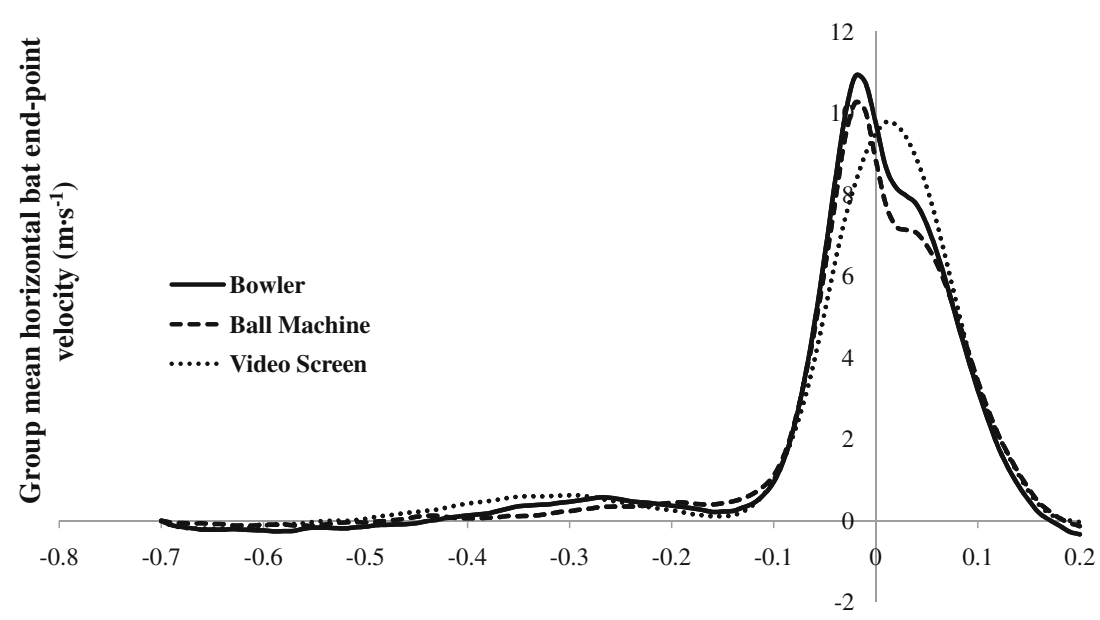

Time (s) facing a "live" bowler. These data provided evidence for the use of advance sources of information to organize movement patterns, available from the kinematics of the bowlers' actions (see Shim et al., 2005; Shim et al., 2006). This observation was particularly evident when one considers that the batters needed to complete one of two fundamentally different tasks:- that is, making a definitive movement forward (for the drive or the defense) or backward (against shorter pitching trials). Due to subtle changes of the ball projection machine head between trials (allowing us to randomize angle of delivery and, therefore, pitching length), the batters in this study were unaware of upcoming delivery characteristics in advance, a concern with previous research involving ball projection machines (Gibson \& Adams, 1989; Renshaw et al., 2007). The use of perceptual information from the bowler's actions allowed batters to significantly increase peak bat swing heights and step lengths (see Fig. 5), similar to findings from previous research in which tennis players were observed to use advance information sources from an opponent's actions to increase their court movement coverage by up to $1.2 \mathrm{~m}$ (Shim et al., 2005). Importantly, the finding that batters displayed lower backswing heights and shorter step lengths when completing a forward defense, as compared with the forward drive, supports previous work (Stretch et al., 1998). This observation confirms that the batters were able to decide on the required stroke before the downswing began, on the basis of advance kinematic and early ball flight information. Comparatively, similar variations in movement responses were observed when they batted against a ball projection machine, even with the removal of prerelease information sources from the bowler, albeit occurring significantly later. Significant delays in backswing and front foot movement initiation times of 80 and $100 \mathrm{~ms}$, respectively, required batters to functionally adapt their actions (implement lower peak bat swing heights and shorter step lengths; see Fig. 5) to ensure a degree of task success. However, batters demonstrated significantly lower performance scores (QOC; see Fig. 2) and lower peak bat swing velocities (10.62 vs. $\left.11.38 \mathrm{~m} \cdot \mathrm{s}^{-1}\right)$ when compared with batting against a "live" bowler. Batters attained peak bat velocities just before the point of bat-ball contact $(-0.02 \mathrm{~s})$ under both interceptive task conditions (Stretch et al., 1998), demonstrating the use of prospective information from ball flight characteristics for the timing of interception. Prospective information is information about the current future; that is, the performer is informed about the future outcomes if the current state is maintained (Montagne, Bastin \& Jacobs, 2008). Hence, it provides information for the modification of movement, allowing performers to adapt behavior independently of specific task constraints. However, critical delays in movement timing imposed by the task constraints (through removal of key perceptual information) could not be offset by the batters' prospectively controlling spatiotemporal characteristics of the action on the basis of ball flight information alone. Interestingly, the strong within-task relationships between time of downswing initiation and point of bat-ball contact suggested that the changes in timing of downswing initiation were caused by differences in the information available between tasks. For example, the batters produced equally consistent timings for downswing initiations in the ball projection machine condition, but these occurred significantly later (closer to point of bat-ball contact) than initiations against a "live" bowler.

The added temporal constraint imposed by the ball machine task constraints in this study raises concerns over experimental and learning task designs that exclude anticipatory perceptual sources. It appears that much of the current data on perceptual anticipation (e.g., gaze behaviors or movement-based skill differences) is based on experimental designs that are not representative of human performance contexts such as sport. It is possible that current data on technical and perceptual characteristics 
(e.g., visual search) differences across skill levels in cricket batting (e.g., Land \& McLeod, 2000; Weissensteiner et al., 2009) may be confounded by the amount of task-specific practice that participants have been exposed to against ball projection machines in developmental programs (e.g., U15 to adult-level programs). In these programs, some batters may have been essentially learning a task different from that required in actual performance environments.

\section{"Live" bowler-video simulation comparisons}

Our results showed that batters were able to achieve the same temporal advantage against a "live" bowler and in video simulation conditions, demonstrating comparable movement organization for the critical early movement initiations (i.e., preparatory actions of backswing and front foot movement). Backswing and front foot movement initiation points occurred $\sim 60$ and $130 \mathrm{~ms}$ after ball release, respectively, under both task constraints. This performance characteristic supported equivalent peak bat swing heights and step lengths across shot types (see Fig. 5). Batters were able to pick up and use pre-ball release information and information from the first portion of ball flight, from a "live" bowler and when it was presented in a video simulation.

These findings might be considered in light of advances in behavioral neuroscience (visual system functioning). Requiring batters to couple movements to video-simulated information on a screen enabled comparison with information provided by a "live" bowler. This methodological advance helped address concerns over speed/accuracy trade-offs (e.g., requiring participants to "react as quickly as possible" in tests of perceptual skill), which seem to have confounded previous studies in visual anticipation (see van der Kamp et al., 2008). Data from our study demonstrated that junior batters' perceptions, decision making, and initial movement responses in this specific video simulation task were representative of similar processes observed in a "live" bowler condition. Action fidelity was supported, and performance in one context (initial movements against a video simulation) statistically corresponded with performance in the other context (e.g., that of a "live" bowler). This finding, while inconsistent with some previous work comparing in situ and video-based designs (e.g., Dicks et al., 2010), may be attributable to the maintenance of a fully simulated action (coupled response), rather than a simplified micro-movement reaction (such as a movement in the anticipated direction). Because of this methodological advance, the video simulation allowed batters to couple preparatory movements to the prerelease and early ballflight information. Many researchers have previously alluded to the possibility of using video simulation designs to study or train visual anticipation processes (Abernethy,
Wood, \& Parks, 1999; Rowe \& McKenna, 2001; Williams, Ward, \& Chapman, 2003). Our data suggest that video simulations may indeed provide representative performance tasks for assessing (or training) affordance perception in developing athletes. However, it remains unclear whether this method could result in the same affordance perception (attunement to subtle but critical changes in response requirements) or efficient and accurate action production without the requirement for simulated movement performance by participants (see van der Kamp et al., 2008). An important finding from this experiment is that, when perception for action is available (under video simulation constraints), it enables a higher fidelity of the initial simulated action responses than when an interceptive action is performed without the availability of representative perceptual variables (under ball machine conditions). These data provide a demonstration of the theoretical role of affordances in guiding skilled actions and are a relevant indication for the strategy of manipulating key task constraints in training sessions. Further work is needed to understand how the pickup of affordances for action may be incorporated into learning designs in developmental sport programs.

The most pronounced differences in our batting data provided clear evidence for concerns over generalizing observations between experimental tasks that lack fidelity of performance characteristics. Changes in the initiation of the downswing and peak bat swing velocities demonstrated a prospective control strategy, with batters' comparing the perceived current state of the environment (e.g., time to contact) with the requirements for successful interception (Fajen et al., 2009; Montagne, 2005). The a priori concern that 2-D simulation displays do not provide sufficient information on ball flight characteristics to support actions such as interceptions was vindicated by observations of significant differences in timing of downswing initiation and markedly lower peak bat swing velocities compared to when participants batted against a "live" bowler. Furthermore, data on the time at which peak bat swing time was attained by the batters under video simulation conditions poses some challenges for such experimental designs. For example, in the video simulation task constraints, peak bat velocity occurred after the point at which interception was predicted to have occurred (see Fig. 6). Batters were unable to accurately judge movement requirements without actual ball flight and bounce location information, both of which are important for enhancing the quality of interceptive actions (see Müller et al., 2009). Either batters were not able to attune to this information, or it could not be faithfully represented in the 2-D video simulation methodology. Our findings offer further support for previous research demonstrating that the assessment of perceptualmotor performance using video-based simulation paradigms, 
particularly when perception and action are decoupled, can lead to serious errors by participants in judging projectile interception location (for a collation of assessment studies, see van der Kamp et al., 2008). Additionally, some possible limitations of other methods of assessing interceptive timing (e.g., comparison with coaches' predictions; Taliep et al., 2007) and possible differences in the level of experience that batters had in the three distinct conditions in the present study should be acknowledged as issues in need of further study.

\section{Conclusions}

The results of the present study revealed significant differences in performance of developmental batters between a representative practice task (batting against a "live" bowler) and both video simulation and ball projection machine task constraints, traditionally used in the assessment of perceptual-motor skill in ball sports. The results demonstrated that the batters were able to functionally adapt behavior for each specific set of task constraints (e.g., the regulation of spatial characteristics under ball machine task constraints to account for delays in movement initiations). However, the removal of key perceptual variables to support action (both prerelease and actual ball flight) suggested that empiricists should be cautious in interpreting which aspects can be generalized from experimental to performance task constraints (e.g., kinetic and kinematic variables; Taliep et al., 2007). It is feasible that current popular experimental designs may actually be limiting progress in understanding and training perceptual and technical abilities of developmental performers in ball sports. In order to better understand the characteristics of perceptual-motor skill and how to develop them, empiricists should attempt to design experimental task constraints that are representative of specific performance contexts. The representative task adopted in the present study was that of a normal practice context in the sport of cricket. Some may argue that differences may exist between observations of batting performance against a "live" bowler in a different context (e.g., competitive sport). This concern was beyond the scope of the present study and is an important question for future research to assess. Future work should also focus on the assessment of learning design across various skill levels and temporal constraints (ball speeds), to assess how informational variables are used at different performance development levels. Indeed, it is currently unknown whether the findings regarding video simulations presented here would also be observed in groups of highly skilled or senior batters in elite sport programs, and this is another aspect that should be investigated in future work. However, there are both empirical (Renshaw et al., 2007) and experiential (Renshaw \& Chappell, 2010) reports showing similar findings for senior and skilled batters.

The first stage of truly understanding how skilled performance in interceptive actions can be developed must be to measure and formally describe tasks that adequately capture the functional behavior of individuals in a specific performance environment, before posing questions on how individuals achieve knowledge about that environment (Araújo \& Davids, 2009; Fajen et al., 2009; Pinder et al., in press). The concept of action fidelity could be used to examine whether a performer's responses (e.g., actions or decisions based on availability of perceptual information) are the same under various task constraints. The use of technological advances-for example, accelerometers and gyroscopes (e.g., Busch \& James, 2007) - may allow for an enhanced understanding and more detailed analysis of the adaption of movement responses under changing task constraints.

Author Note This article was written while the first author was supported by a Queensland University of Technology International Postgraduate Scholarship Award. We would like to thank Brisbane Grammar School and Darren Holder for providing access to the training facility and to participants for their commitment and involvement in the study. We also would like to acknowledge the three anonymous reviewers for their insightful and valuable comments on earlier versions of the manuscript.

\section{References}

Abernethy, B., Wood, J. M., \& Parks, S. L. (1999). Can the anticipatory skills of experts be learned by novices? Research Quarterly for Exercise and Sport, 70, 313-318.

Abernethy, B., \& Zawi, K. (2007). Pickup of essential kinematics underpins expert perception of movement patterns. Journal of Motor Behavior, 39, 353-367.

Abernethy, B., Zawi, K., \& Jackson, R. C. (2008). Expertise and attunement to kinematic constraints. Perception, 37, 931-948.

ACB. (1998). Australian cricket board national pace bowling program resource kit. Melbourne: Australian Cricket Board.

Araújo, D. (2007). Promoting ecologies where performers exhibit expert interactions. International Journal of Sport Psychology, $38,73-77$.

Araújo, D., \& Davids, K. (2009). Ecological approaches to cognition and action in sport and exercise: Ask not only what you do, but where you do it. International Journal of Sport Psychology, 40, 5-37.

Araújo, D., Davids, K., \& Hristovski, R. (2006). The ecological dynamics of decision making in sport. Psychology of Sport and Exercise, 7, 653-676.

Araújo, D., Davids, K., \& Passos, P. (2007). Ecological validity, representative design, and correspondence between experimental task constraints and behavioral setting: Comment on Rogers, Kadar, and Costall (2005). Ecological Psychology, 19, 69-78.

Atkinson, G., \& Nevill, A. M. (1998). Statistical methods for assessing measurement error (reliability) in variables relevant to sports medicine. Sports Medicine, 26, 217-238.

Bartlett, R. M. (2007). Introduction to sports biomechanics: Analysing human movement patterns. New York: Routledge. 
Brunswik, E. (1956). Perception and the representative design of psychological experiments (2nd ed.). Berkeley: University of California Press.

Busch, A., \& James, D. (2007). Analysis of cricket shots using inertial sensors. In A. Subic, F. K. Fuss, \& S. Ujihashi (Eds.), The impact of technology on sport II (pp. 317-322). London: Taylor \& Francis.

Caljouw, S. R., van der Kamp, J., \& Savelsbergh, G. J. P. (2004). Timing of goal-directed hitting: Impact requirements change the information-movement coupling. Experimental Brain Research, $155,135-144$.

Croft, J. L., Button, C., \& Dicks, M. (2010). Visual strategies of sub-elite cricket batsmen in response to different ball velocities. Human Movement Science, 29, 751-763.

Davids, K. (2008). Designing representative task constraints for studying visual anticipation in fast ball sports: What we can learn from past and contemporary insights in neurobiology and psychology. International Journal of Sport Psychology, 39, 166177.

Davids, K., Button, C., Araújo, D., Renshaw, I., \& Hristovski, R. (2006). Movement models from sports provide representative task constraints for studying adaptive behavior in human movement systems. Adaptive Behavior, 14, 73-95.

Davids, K., Renshaw, I., \& Glazier, P. (2005). Movement models from sports reveal fundamental insights into coordination processes. Exercise and Sport Science Reviews, 33, 36-42.

Dhami, M. K., Hertwig, R., \& Hoffrage, U. (2004). The role of representative design in ecological approach to cognition. Psychological Bulletin, 130, 959-988.

Dicks, M., Button, C., \& Davids, K. (2010). Examination of gaze behaviors under in situ and video simulation task constraints reveals differences in information pickup for perception and action. Attention, Perception, \& Psychophysics, 72, 706-720.

Dicks, M., Davids, K., \& Araújo, D. (2008). Ecological psychology and task representativeness: Implications for the design of perceptual-motor training programmes in sport. In Y. Hong \& R. Bartlett (Eds.), The Routledge handbook of biomechanics and human movement science (pp. 129-139). London: Routledge.

Dunwoody, P. T. (2006). The neglect of the environment by cognitive psychology. Journal of Theoretical and Philosophical Psychology, 26, 139-153.

Fajen, B. R., Riley, M. A., \& Turvey, M. T. (2009). Information, affordances and the control of action in sport. International Journal of Sport Psychology, 40, 79-107.

Field, A. (2009). Discovering statistics using SPSS (3rd ed.). London: Sage.

Gibson, J. J. (1966). The senses considered as perceptual systems. Boston: Houghton Mifflin.

Gibson, J. J. (1979). The ecological approach to visual perception. Boston: Houghton Mifflin.

Gibson, A. P., \& Adams, R. D. (1989). Batting stroke timing with a bowler and a bowling machine: A case study. Australian Journal of Science and Medicine in Sport, 21, 3-6.

Hammond, K. R., \& Stewart, T. R. (Eds.). (2001). The essential Brunswik: Beginnings, explications, applications. New York: Oxford University Press.

Jackson, R. C., \& Morgan, P. (2007). Advance visual information, awareness, and anticipation skill. Journal of Motor Behavior, 39, $341-351$

Jacobs, D. M., \& Michaels, C. F. (2002). On the apparent paradox of learning and realism. Ecological Psychology, 14, 127-139.

Land, M. F., \& McLeod, P. (2000). From eye movements to actions: How batsmen hit the ball. Nature Neuroscience, 3, 1340-1345.

Le Runigo, C., Benguigui, N., \& Bardy, B. G. (2005). Perception-action and expertise in interceptive actions. Human Movement Science, 24, $429-445$.
Mann, D. L., Abernethy, B., \& Farrow, D. (2010). The resiliance of natural interceptive actions to refractive blur. Human Movement Science, 29, 386-400.

Mann, D. L., Ho, N. Y., De Souza, N. J., Watson, D. R., \& Taylor, S. J. (2007). Is optimal vision required for the successful execution of an interceptive task? Human Movement Science, 26, 343-356.

Mann, D. T. Y., Williams, A. M., Ward, P., \& Janelle, C. M. (2007) Perceptual-cognitive expertise in sport: A meta-analysis. Journal of Sport \& Exercise Psychology, 29, 457-478.

McIntyre, D. R., \& Pfautsch, E. W. (1982). A kinetic analysis of the baseball swings involved in opposite-field and same-field hitting. Research Quarterly for Exercise and Sport, 53, 206-213.

Messier, S. P., \& Owen, M. G. (1984). Bat dynamics of female fast pitch softball players. Research Quarterly for Exercise and Sport, $55,141-145$.

Montagne, G. (2005). Prospective control in sport. International Journal of Sport Psychology, 36, 127-150.

Montagne, G., Bastin, J., \& Jacobs, D. M. (2008). What is visual anticipation and how much does it rely on the dorsal stream? International Journal of Sport Psychology, 39, 149-156.

Montagne, G., Laurent, M., Durey, A., \& Bootsma, R. (1999). Movement reversals in ball catching. Experimental Brain Research, 129, 87-92.

Müller, S., \& Abernethy, B. (2006). Batting with occluded vision: An in situ examination of the information pick-up and interceptive skills of high- and low-skilled cricket batsmen. Journal of Science and Medicine in Sport, 9, 446-458.

Müller, S., \& Abernethy, B. (2008). Validity and reliability of a simple categorical tool for the assessment of interceptive skill. Journal of Science and Medicine in Sport, 11, 549-552.

Müller, S., Abernethy, B., Reece, J., Rose, M., Eid, M., McBean, R., et al. (2009). An in-situ examination of the timing of information pick-up for interception by cricket batsmen of different skill levels. Psychology of Sport and Exercise, 10, 644-652.

Pinder, R. A., Davids, K., Renshaw, I., \& Araújo, D. (in press). Representative learning design and functionality of research and practice in sport. Journal of Sport \& Exercise Psychology.

Pinder, R. A., Renshaw, I., \& Davids, K. (2009). Informationmovement coupling in developing cricketers under changing ecological practice constraints. Human Movement Science, 28 , 468-479.

Regan, D. (1997). Visual factors in hitting and catching. Journal of Sports Sciences, 15, 533-558.

Renshaw, I., \& Chappell, G. S. (2010). A constraints-led approach to talent development in cricket. In L. Kidman \& B. Lombardo (Eds.), Athlete-centred coaching (2nd ed., pp. 151-172). Christchurch: Innovative.

Renshaw, I., \& Fairweather, M. M. (2000). Cricket bowling deliveries and the discrimination ability of professional and amateur batters. Journal of Sports Sciences, 18, 951-957.

Renshaw, I., Oldham, A. R. H., Davids, K., \& Golds, T. (2007). Changing ecological constraints of practice alters coordination of dynamic interceptive actions. European Journal of Sport Science, 7, 157-167.

Rogers, W. A. (2008). Editorial. Journal of Experimental Psychology. Applied, 14, 1-4.

Rowe, R. M., \& McKenna, F. P. (2001). Skilled anticipation in real-world tasks: Measurement of attentional demands in the domain of tennis. Journal of Experimental Psychology. Applied, 7, 60-67.

Savelsbergh, G. J. P., \& Bootsma, R. J. (1994). Perception-action coupling in hitting and catching. International Journal of Sport Psychology, 25, 331-343.

Shibayama, H., \& Ebashi, H. (1983). Development of a motor skill using the golf swing from the viewpoint of the regulation of muscle activity. In H. Matsui \& K. Kobayashi (Eds.), Biomechanics VIII (pp. 895-902). Champaign: Human Kinetics. 
Shim, J., Carlton, L. G., Chow, J. W., \& Chae, W. K. (2005). The use of anticipatory visual cues by highly skilled tennis players. Journal of Motor Behavior, 37, 164-175.

Shim, J., Carlton, L. G., \& Kwon, Y. H. (2006). Perception of kinematic characteristics of tennis strokes for anticipating stroke type and direction. Research Quarterly for Exercise and Sport, 77, 326-339.

Stoffregen, T. A., Bardy, B. G., Smart, L. J., \& Pagulayan, R. (2003). On the nature and evaluation of fidelity in virtual environments. In L. J. Hettinger \& M. W. Haas (Eds.), Virtual and adaptive environments: Applications, implications and human performance issues (pp. 111-128). Mahwah: Erlbaum.

Stretch, R. A., Buys, F., Du Toit, E., \& Viljoen, G. (1998). Kinematics and kinetics of the drive off the front foot in cricket batting. Journal of Sports Sciences, 16, 711-720.

Taliep, M. S., Galal, U., \& Vaughan, C. L. (2007). The position of the head and centre of mass during the front foot off-drive in skilled and less-skilled cricket batsmen. Sports Biomechanics, 6, 345-360.

van der Kamp, J., Rivas, F., van Doorn, H., \& Savelsbergh, G. (2008). Ventral and dorsal contributions in visual anticipation in fast ball sports. International Journal of Sport Psychology, 39, 100-130.
Vincent, J. (1994). Statistics in kinesiology. Champaign: Human Kinetics.

Warren, W. H. (2006). The dynamics of perception and action. Psychological Review, 113, 358-389.

Weissensteiner, J., Abernethy, B., \& Farrow, D. (2009). Examining the development of technical skill in cricket batting. Paper presented at the 7th Australasian Biomechanics Conference, Gold Coast, Queensland, Australia. November-December.

Weissensteiner, J., Abernethy, B., Farrow, D., \& Müller, S. (2008). The development of anticipation: A cross-sectional examination of the practice experiences contributing to skill in cricket batting. Journal of Sport \& Exercise Psychology, 30, 663-684.

Williams, A. M., \& McRobert, A. (2008). Perceptual-cognitive skills in cricket batting: From testing to training. In T. Reilly (Ed.), Science and sports: Bridging the gap. Maastricht: Shaker.

Williams, A. M., Ward, P., \& Chapman, C. (2003). Training perceptual skill in field hockey: Is there transfer from the laboratory to the field? Research Quarterly for Exercise and Sport, 74, 98-103.

Woolmer, B., Noakes, T. D., \& Moffett, H. (2008). Bob Woolmer's art and science of cricket. London: New Holland. 